\title{
Development of a Destabilized Firefly Luciferase Enzyme for Measurement of Gene Expression
}

\author{
Gilles M. Leclerc, Fredric R. \\ Boockfor, William J. Faught \\ and L. Stephen Frawley \\ Medical University of South \\ Carolina, Charleston, SC, USA
}

\begin{abstract}
Firefly luciferase is used widely as a reporter enzyme for studies of gene regulation and expression. The recent development of new technologies that combine luciferase reporter technology and digital imaging microscopy has enabled multiple measurements of gene expression in the same living cell. Although this approach has already provided new insights about expression $d y$ namics, its future utility is limited by the three- to four-hour half-life of firefly luciferase in mammalian cells. Because of this, rapid increases or decreases in gene expression may not be detected, owing to the accumulation of residual luciferase. Accordingly, the goal of the present study was to develop a luciferase reporter with a reduced functional half-life. This was accomplished by adding a synthetic fragment to the firefly luciferase-coding sequence that encoded the proteolytic "PEST" signal from mouse ornithine decarboxylase. When placed under the control of estrogen response elements and expressed in human breast cancer $T$ $47 D$ cells, the modified luciferase protein (LUCODC-DA) displayed a functional halflife of $0.84 \mathrm{~h}$ compared to $3.68 \mathrm{~h}$ for the wild-type enzyme. As anticipated, the overall rate of photonic emissions in cells expressing the destabilized luciferase was about sevenfold lower than that of their wild-type counterparts, presumably because of the reduction of steady-state luciferase accumulation. Even so, the photonic activity derived from LUCODC-DA was still sufficient to enable real-time measurements of gene expression in single living cells.
\end{abstract}

\section{INTRODUCTION}

Recent advances in reporter gene technology combined with significant developments in digital imaging microscopy now enable molecular processes such as gene expression to be visualized in living cells. Our laboratory has made good use of these technological advances to achieve dynamic monitoring and quantification of hormonal gene expression in single, viable pituitary cells, breast cancer cells and neurons $(1,2,5,19,28,29)$. The sensitivity and temporal resolution of these new strategies depend largely on the biological properties of the reporter used to monitor gene expression; luciferase has proved to be particularly well suited for real-time imaging applications (24).

Luciferase cDNAs from the firefly Photinus pyralis, the sea pansy Renilla reniformis and selected beetle species have been cloned and expressed in $E$. coli and in many eukaryotic cell types $(3,4,15-17,32)$. The firefly luciferase gene encodes a $62-\mathrm{kDa}$ monomeric protein that generates a bioluminescent signal by catalyzing the oxidation of its substrate luciferin (31). The decay rate of the luciferase enzyme has been estimated to be approximately $3-4 \mathrm{~h}$ in mammalian cells (27), which makes it suitable for detecting dynamic changes in the rate of gene expression that might evolve over the course of several hours or days. However, the capacity to detect shorter-term changes of gene expression is limited, owing to the residual photonic contribution of preexisting luciferase within the cell. The $3-4 \mathrm{~h}$ half-life $\left(\mathrm{t}_{1 / 2}\right)$ of firefly luciferase becomes particularly problematic in attempts to monitor a diminution of gene expression. Thus, the development of a destabilized form of luciferase would satisfy this need for a more responsive reporter protein.
Rapid turnover in proteins is often caused by signals that induce protein degradation $(10,23)$. One of the best characterized of these proteolytic signals was identified as a region enriched in proline $(\mathrm{P})$, glutamate $(\mathrm{E})$, serine $(\mathrm{S})$ and threonine (T) residues (PEST) and flanked by positively charged residues such as lysine $(\mathrm{K})$, arginine (R) or histidine $(H)(21,23)$. This PEST domain is composed of at least 12 hydrophilic amino acid residues and can be distributed anywhere along the polypeptide chain. Proteins may contain multiple PEST sequences that can act as constitutive or conditional proteolytic signals for intracllular degradation of key metabolic proteins (22). The role of the PEST domain in protein degradation is supported by both mutational experiments (7) and experimental transfer of the PEST domain from mouse ornithine decarboxylase (mODC) to metabolically stable proteins $(6,12-14)$. Mammalian ODC has one of the shortest $t_{1 / 2}$ described for animal enzymes (10-60 min) $(8,9,23)$, and attachment of the PEST degradation signal of mODC (amino acids 422-461) to the carboxyl-COOH-terminal region of the enhanced green fluorescent protein (EGFP) reporter gene decreased its $t_{1 / 2}$ sixfold in mammalian cells (13). Mutation of key amino acids in the PEST domain indicated that at least one P, E, S and $\mathrm{T}$ was required for protein degradation. Also, protein degradation was not correlated with the number of PEST residues but with their relative position within the PEST domain (13). Taken together, it is clear that the presence of the PEST domain within a protein can have a dramatic influence on its $t_{1 / 2}$.

The goal of the present study was to construct a reporter plasmid encoding a destabilized form of firefly luciferase. This was accomplished by cloning a 
PEST mODC sequence variant (derived from the mODC carboxyl$\mathrm{COOH}$-terminal region) downstream of the luciferase gene. The PEST mODCDA variant was synthetically reconstituted using PCR technology. Upon expression, this resulted in a firefly luciferase-mODC-DA/PEST hybrid protein (LUCODC-DA). The stability of this protein was evaluated in cultures of human breast cancer T-47D cells. The functionality of the LUCODC-DA variant as a reporter was demonstrated in single living cells using a photoncapture microscopic system that enabled real-time measurement of gene expression. Our results indicate that this destabilized luciferase enzyme should provide a more sensitive reporter to detect and resolve fast and transient changes in gene expression patterns in living cells.

\section{MATERIALS AND METHODS}

\section{T-47D Cell Culture, Chemical Transfection and Microinjection}

Populations of human breast carcinoma T-47D cells (HTB-133; ATCC, Manassas, VA, USA) were maintained in phenol-free RPMI 1640 medium supplemented with $2 \mathrm{mM}$ L-glutamine, $1 \mathrm{mM}$ sodium pyruvate, $10 \mathrm{mM}$ HEPES, $10000 \mathrm{U} / \mathrm{mL}$ penicillin, $10 \mathrm{mg} / \mathrm{mL}$ streptomycin, $10 \mu \mathrm{g} / \mathrm{mL}$ bovine insulin and $10 \%$ fetal bovine serum (n-FBS) (Life Technologies, Rockville, MD, USA) in a $95 \%$ air $/ 5 \% \mathrm{CO}_{2}$ environment at $37^{\circ} \mathrm{C}$. Under these conditions, cells were grown as a monolayer in accordance with routine cell-culture procedures.

The T-47D cells were transfected following a chemical procedure using the LIPOFECTAMINE ${ }^{\mathrm{TM}}$ reagent (Life Technologies) as described elsewhere (30). Briefly, cells were plated in 6-well tissue-culture microplates $\left(\right.$ Falcon ${ }^{\circledR}$; Becton Dickinson, Franklin Lakes, NJ, USA) at a concentration of 200000 cells/well in phenol-free RPMI 1640 supplemented with $10 \%$ charcoalstripped FBS (cs-FBS) for $24 \mathrm{~h}$ before chemical transfection. An amount of 2 $\mu \mathrm{g}$ EndoFree $^{\mathrm{TM}}$-purified plasmid DNA (Qiagen, Valencia, CA, USA) and 10 $\mu \mathrm{L}$ LIPOFECTAMINE reagent were used for each transfection. The cells were incubated for $5 \mathrm{~h}$ with the DNA-LIPOFECTAMINE complexes at $37^{\circ} \mathrm{C}$ in a $5 \%$ $\mathrm{CO}_{2}$ incubator. Following the incubation, the cells were washed with phenol/serum-free RPMI 1640 medium, covered with $2 \mathrm{~mL}$ fresh RPMI 1640 medium supplemented with $10 \%$ csFBS and $1 \mathrm{nM} 17 \beta$-estradiol (Sigma, St. Louis, MO, USA); they were then incubated at $37^{\circ} \mathrm{C}$ in the presence of $5 \% \mathrm{CO}_{2}$ for $48 \mathrm{~h}$ before any treatments.

Other cells were subjected to microinjection using a semiautomated micromanipulator and an injector system (both from Eppendorf, Hamburg, Germany) as described by Willard et al. (29). In brief, culture flasks containing untransfected cells were trypsinized (0.05\% trypsin, $0.53 \mathrm{mM}$ EDTA; Life Technologies) to yield a suspension of monodispersed cells. Cells were then plated on alphanumeric, gridded coverslips at a concentration of 30000 cells in $200 \mu \mathrm{L}$ RPMI 1640 supplemented with $10 \% \mathrm{n}$-FBS for $1 \mathrm{~h}$ to allow attachment. Then, $1.7 \mathrm{~mL}$ of the same medium were added to each well containing a coverslip. Cells on coverslips were incubated for $24 \mathrm{~h}$ before microinjection, with the DNA used for microinjection being purified according the EndoFree plasmid kit and diluted to a concentration of $0.4 \mu \mathrm{g} / \mu \mathrm{L}$. Following microinjection, coverslips containing T-47D cells were cultured for another $24 \mathrm{~h}$ before photon counting.

\section{Molecular Cloning, PCR Amplification and DNA Sequencing}

In this study, we used the $E$. coli strain XL1-Blue MRF' as the recipient for all molecular cloning procedures (Stratagene, La Jolla, CA, USA). Bacterial cultures were grown routinely in LB broth at $37^{\circ} \mathrm{C}$ with the addition of $50 \mu \mathrm{g} / \mathrm{mL}$ ampicillin when required. Extraction and purification of plasmid DNA were performed using a plasmid purification kit (Qiagen). Restriction enzymes were used in accordance with the manufacturer's recommendations (New England Biolabs, Beverly, MA, USA). The vector pEMlux 85B, used for the cloning experiments, derives from the pMAMneo-LUC (Clontech Laboratories, Palo Alto, CA, USA) (GenBank $^{\circledR}$ accession no. U02448) and 
contains the wild-type firefly luciferase cDNA gene fused to the estrogen response element (ERE) 5 -MMTV gene promoter (18). This estrogenic promoter was used to drive the expression of the firefly luciferase and was induced by the addition of $17 \beta$-estradiol. To produce the synthetic mODC PEST LUCODC-DA domain, we designed six oligonucleotides based on the DNA sequences corresponding to the $3^{\prime}$-end of the luciferase and the mODC genes (Figure 1). These oligonucleotides were synthesized and gel purified by Integrated DNA Technologies (Coralville, IA, USA). Their nucleotide sequences (with the EcoNI and SpeI sites underlined) were as follows: LUCO DC-F1 (5'-AAAATCAGAGAGATC CTCATAAAGCCCA-3'); LUCODC-R2 (5'-GGAAGCCATGGTAAGCTTG
GACTTTCCGCCCTTCTTGGCCTTTATGAGGAT-3'); LUCODC-F3DA (5'-TAGCCATGGCTTCCCGCCG GAGGTGGAGGAGCAGGCTGCTG GCACGCTGCCCA-3'); LUCODC-R4 (5'-AGGGTGACGGTCCATCCCGCTCTCCTGGGCACAAGACATGGGCAGCGTGCCAT-3'); LUCODC-F5 (5'-ATGGACCGTCACCCTGCAGC CTGTGCTTCTGCTAGGATCAAT GTGTAGATG-3') and LUCODC-R6INV(5'-CTGAATACTAGT TACATCTACACATTGATC-3'). The PEST domain was reconstituted using a PCR procedure described elsewhere (26). The oligonucleotides LUCODC-F1 and -R6INV were used as PCR primers at a concentration of $0.5 \mu \mathrm{M}$.

Each of these two primers contained a unique restriction site at its $5^{\prime}$-end (EcoNI and SpeI) to facilitate cloning.

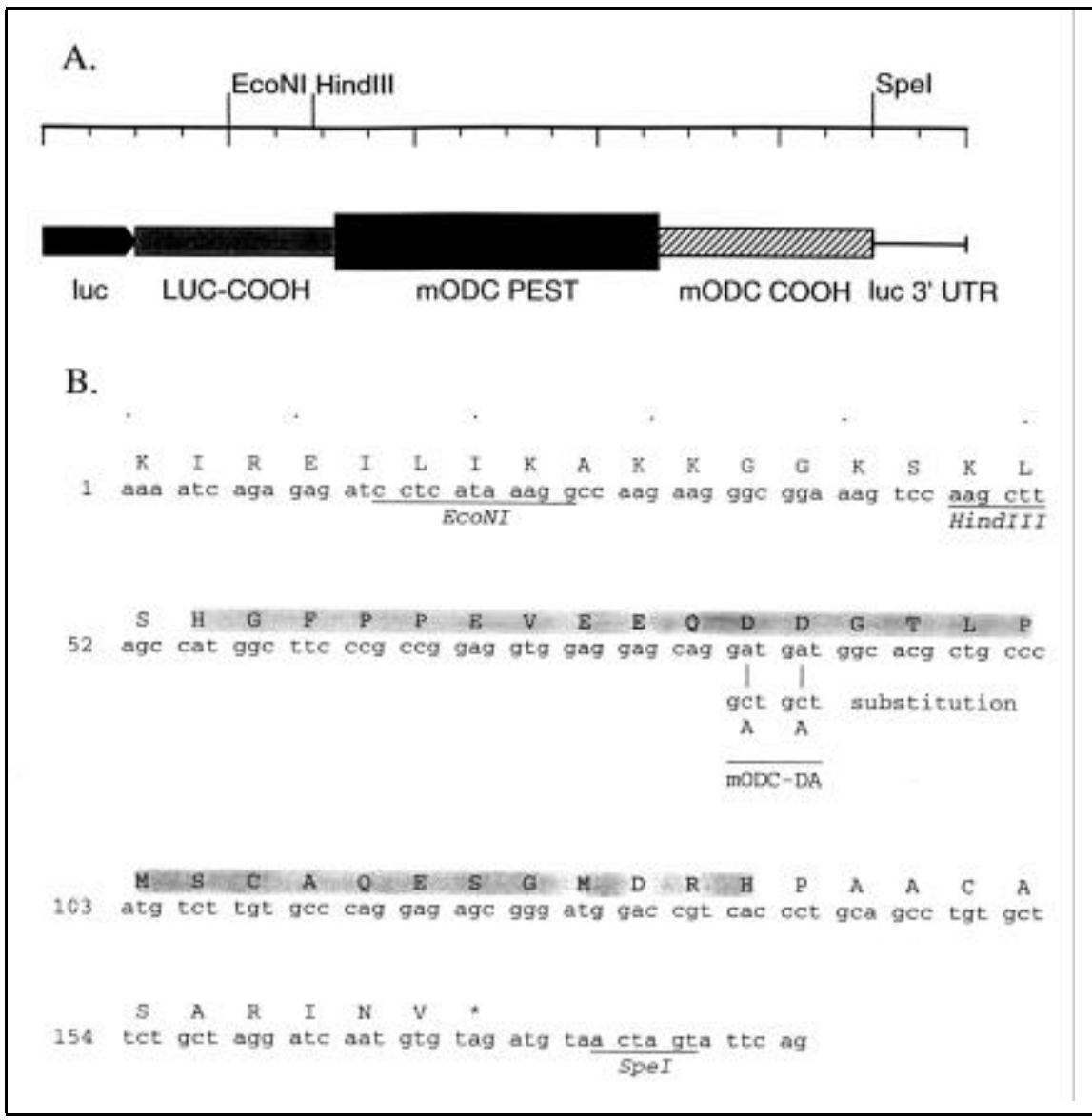

Figure 1. Schematic representation of the PEST sequence used to destabilize firefly luciferase. (A) Graphic map of the LUCODC fragment. (B) Nucleotide sequences of the synthetic PEST LUCODC domain. The nucleotides numbered $1-51$ correspond to the $3^{\prime}$-end coding region of the luciferase gene (4). Single-letter codes for the corresponding amino acids are placed above their respective DNA sequence. The PEST domain is highlighted in gray and corresponds to amino acids 423-450 of the mODC protein (11). The restriction sites EcoNI, HindIII and SpeI are underlined. Substitutions of amino acids D433A and D434A (mODC-DA) are shown below the sequence. * denotes the end of the coding sequence.

The oligonucleotides LUCODC-R2, -F3DA, -R4 and -F5, representing the "core sequence" of the synthetic fragment, were used at a concentration of 10 nM. Each oligonucleotide was added to a mixture $(50 \mu \mathrm{L})$ containing $1 \times P f u$ DNA polymerase buffer (Stratagene), $200 \mu \mathrm{M}$ each dNTPs (dATP, dTTP, dGTP and dCTP) (Life Technologies) and $2 \mathrm{U}$ cloned $P f u$ DNA polymerase. The PCR conditions were as follows: initial denaturation for 1 min at $94^{\circ} \mathrm{C}$, followed by 34 amplification cycles (denaturation, $1 \mathrm{~min}$ at $94^{\circ} \mathrm{C}$; annealing, $30 \mathrm{~s}$ at $49^{\circ} \mathrm{C}$; extension, $30 \mathrm{~s}$ at $72^{\circ} \mathrm{C}$ ) and a final extension for $5 \mathrm{~min}$ at $72^{\circ} \mathrm{C}$. The $191-\mathrm{bp} \mathrm{LU}$ CODC-DA PCR-amplified fragment was digested with both EcoNI and SpeI enzymes, extracted and purified from a $5 \%$ polyacrylamide gel (25) and inserted between the EcoNI and SpeI sites of the pEMlux 85B. The recombinant DNA molecules were transformed into E. coli XL1-Blue $\mathrm{MRF}^{\prime}$, and positive clones were selected and transferred to LB-ampicillin plates.

The introduction of a HindIII site within the synthetic fragment allowed rapid and easy screening of positive clones. The validity of the recombinant plasmid DNA, pDA61, was determined by PCR and nucleotide DNA sequencing reactions. Automated DNA sequencing data of isolated plasmid DNA were obtained by the Biotechnology Resource Laboratory of the Medical University of South Carolina. Sequences were analyzed using the SEQED and BESTFIT programs (Genetics Computer Group, Madison, WI, USA).

\section{Luciferase Assay Conditions}

Cell extracts from transfected T-47D cells were prepared using the luciferase assay system (Promega, Madison, WI, USA). The protein concentrations of each cell extract were evaluated with the BCA protein assay reagent without modification (Pierce Chemical, Rockford, IL, USA). Generally, 20- $\mu \mathrm{L}$ volumes of the cell lysate samples were assayed for luciferase activity in a luminometer for $30 \mathrm{~s}$ (AutoLumat ${ }^{\mathrm{TM}} \mathrm{LB}$ 953 AL2; PerkinElmer Life Science, Gaithersburg, MD, USA) and results were expressed as specific photonic emission/mg protein. To determine the 


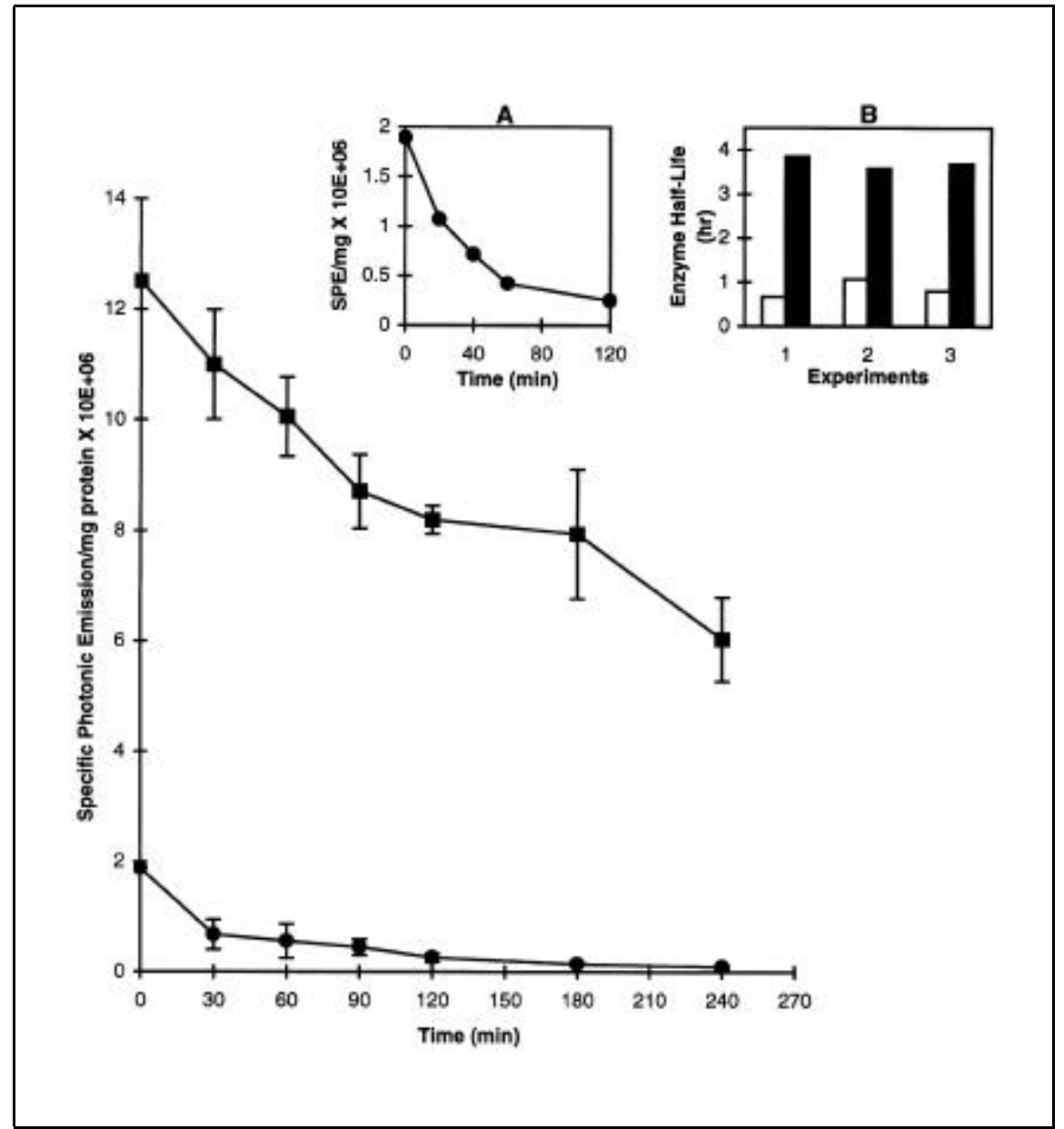

Figure 2. Functional half-life of wild-type and LUCODC-DA luciferases in T-47D cells. T-47D cells transfected with pEMlux85B (squares, wild-type) or pDA61 (circles, LUCODC-DA) were treated with $100 \mu \mathrm{M}$ cycloheximide for various times to block protein synthesis. Cells extracts were prepared and assayed for luciferase activity as described in Materials and Methods. The values represent the mean $( \pm)$ the range ( $30 \mathrm{~min})$ or $( \pm)$ the $\mathrm{SD}(0,60,90,120,180$ and $240 \mathrm{~min})$ of luciferase activity from two or three independent experiments, respectively. For each experiment, triplicate determinations were averaged for every time point. Shown in inset $\mathrm{A}$ is an example of an experiment using the modified luciferase enzyme (pDA61), which includes additional time points measured during the first hour. Inset B represents the calculated half-lives for the LUCODC-DA variant (white bars) and the wild-type (black bars) enzymes obtained for each of the experiments. rate of protein decay, the transfected cells were treated for varying periods of time with cycloheximide $(\mathrm{CHX})$, a protein synthesis inhibitor (20), at a final concentration of $100 \mu \mathrm{g} / \mathrm{mL}$. Data from three independent experiments for each plasmid with three replicates/experiment for each period of treatment with CHX were normalized to their initial activity value. Standard deviations were calculated with Microsoft $^{\circledR}$ Excel $^{\circledR}$ version 5.0c.

\section{Continuous Monitoring of Gene Expression in Single Living Breast Cancer Cells}

Continuous measurement of luciferase enzymatic activity was conducted on T-47D cells transfected by microinjection $24 \mathrm{~h}$ earlier with the PEST-containing plasmid, pDA61. The imaging medium used was RPMI 1640 supplemented with $10 \%$ n-FBS and 0.1 $\mathrm{mM}$ luciferin. Cells were allowed to pre-incubate in this medium for $2 \mathrm{~h}$ at $37^{\circ} \mathrm{C}$ before experimentation. Then, the coverslip containing the cells was assembled in a Sykes-Moore chamber that was connected to a perifusion system (imaging medium flowed at a rate of $10 \mu \mathrm{L} / \mathrm{min}$ ). The combined apparatus was then placed on the heated stage of our photon-capture microscope. Photonic signals were accumulated and quantified continuously in 8-min bins for $16 \mathrm{~h}$. The photon-counting imaging system is described in detail elsewhere (19). Specific photonic emissions for individual cells were computed after subtraction of the background signal.
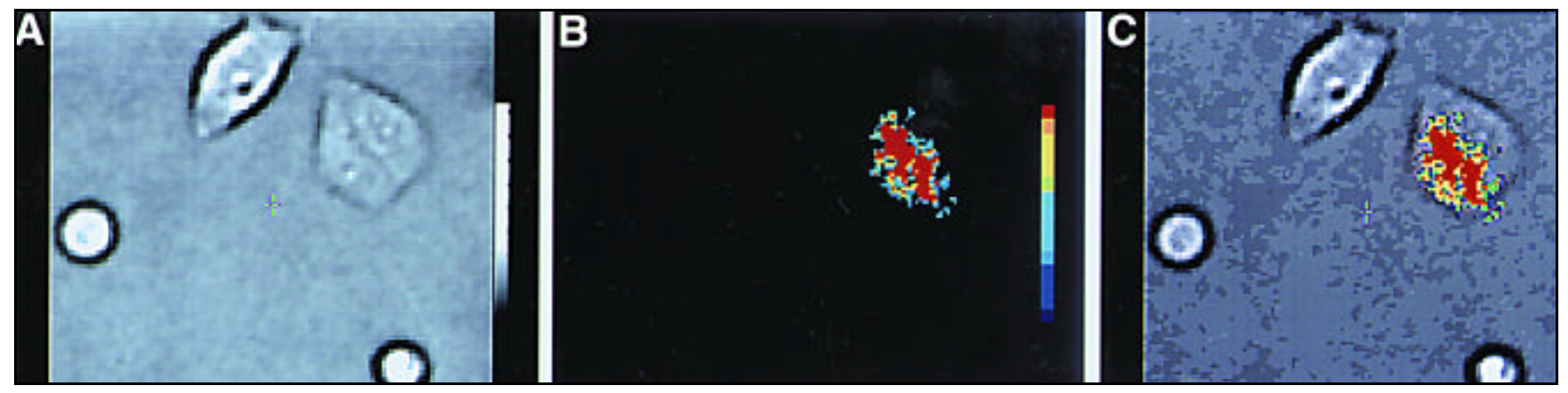

Figure 3. Real-time measurement of estrogen response element-driven LUCODC-DA gene expression from single living T-47D cells. Single T-47D cells were microinjected with the plasmid pDA61 in which the LUCODC-DA variant was expressed under the control of estrogen response elements. Twenty-four hours later, the cells were subjected to photonic analysis as described in Materials and Methods. Panel A shows a bright-field image of transfected cells from which photonic emissions were quantified; panel B illustrates amplified photonic signals from the same microscopic field accumulated over an 8-min period. Superimposition of panels A and B is shown in panel C. Each dot reflects a cloud of photoelectrons detected at the intensifier output after amplification of a single emitted photon. The warmer colors indicate overlapping signals consistent with the ascending pseudocolor scale to the right. 


\section{RESULTS AND DISCUSSION}

\section{Generation of Synthetic PEST Sequences}

To develop a destabilized luciferase enzyme, we constructed a luciferase hybrid protein containing a variant of the mODC PEST domain at its carboxyl $\mathrm{COOH}$-terminal region. The PEST variant used in this study was the mODCDA (D433A/D434A), which induced a high degree of protein degradation in mammalian CHO K1 Tet-off cells (13). In this study, the PEST LUCODC-DA sequence variant was generated by PCR through a set of oligonucleotides spanning an artificial sequence containing the 3 '-end region of the mODC PEST domain (11) (sequence corresponding to amino acids 422-461) fused in frame to the $3^{\prime}$-end region of the firefly luciferase cDNA gene (4) (Figure 1). The resulting LUCODC-DA PCR-amplified fragment was cloned in frame downstream of the luciferase-coding sequence of the pEMlux $85 \mathrm{~B}$ vector, generating the plasmid pDA61 (LUCODC-DA).

Subsequently, the functional activity of the LUCODC-DA enzyme was evaluated at the population level in human breast cancer T-47D cells, chemically transfected with the plasmid pDA61. The results shown in Figures 2 and 3 demonstrate that the LUCODC-DA luciferase variant was active in T-47D cells, indicating that this hybrid protein was expressed and folded properly. Although this modified luciferase enzyme was active, the addition of the PEST domain (encoding 40 amino acids) was found to reduce its overall luciferase activity by approximately sevenfold compared to the unmodified enzyme (Figure 2). A similar overall reduction in activity was observed by $\mathrm{Li}$ et al. (13) with a modified EGFP containing the PEST ODC-DA variant.

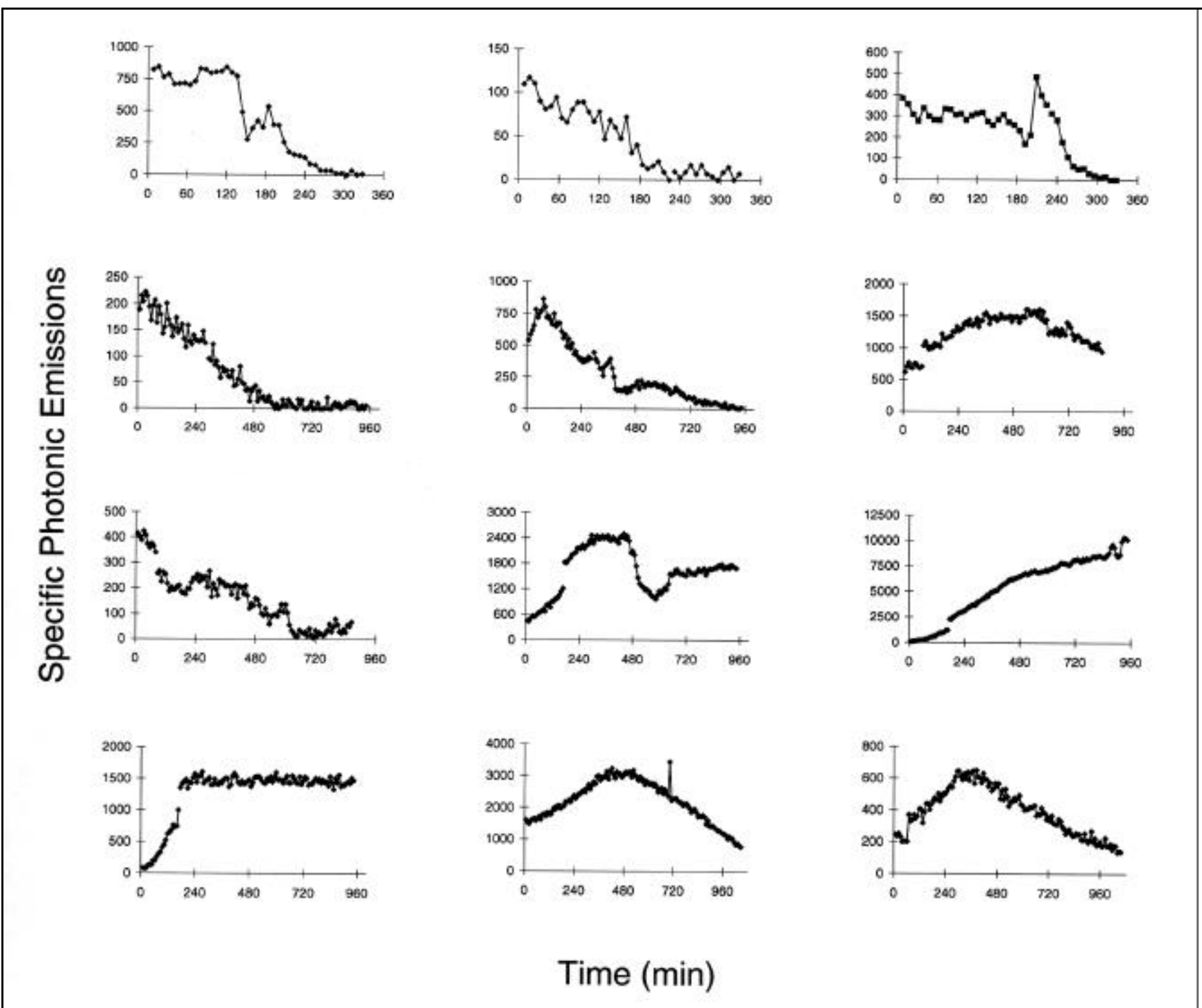

Figure 4. Continuous measurements of LUCODC-DA reporter activity from individual T-47D cells. Shown here are profiles of photonic emissions from cells transfected with the plasmid pDA61 (LUCODC-DA). The luciferase activity for each cell was monitored continuously for several hours, and the data were accumulated in 8-min bins. 
Determination of Functional HalfLife of the LUCODC-DA Luciferase

To determine the functional $t_{1 / 2}$ of the LUCODC-DA variant, populations of T-47D cells were transfected with either plasmid pEMlux85B or pDA61, treated with CHX for $0-4 \mathrm{~h}$ with intervals of $30 \mathrm{~min}$ and assayed for luciferase activity. As Figure 2 shows, the degradation rate exhibited by the modified variant LUCODC-DA $\left(\mathrm{t}_{1 / 2}=0.84\right.$ h) was increased by more than fourfold compared to that of the wild-type luciferase $\left(\mathrm{t}_{1 / 2}=3.68 \mathrm{~h}\right)$. The decay rate determined for the wild-type enzyme was comparable to that published earlier (27). Thus, the appendage of the PEST ODC-DA variant to the already short-lived luciferase enzyme destabilized it even further. This is another example that supports the role of the PEST domain as a proteolytic signal to induce protein degradation.

\section{Analysis of LUCODC-DA Gene Expression in Single Living Human Breast Cancer T-47D Cells}

Since the LUCODC-DA variant exhibited about a sevenfold reduction in overall luciferase activity, we were concerned that this destabilization might have compromised its utility as a realtime indicator of gene expression at the single-cell level. To test its functionality, we microinjected the plasmid pDA61 into individual T-47D cells and measured quantitatively the rate of photonic emissions (reflective of promoterdriven luciferase production) as described in Materials and Methods. Figure 3 shows representative examples of cells expressing the LUCODC-DA luciferase gene and exhibiting a reasonably strong and definitive signal. Figure 4 shows a more quantitative treatment of data, where promoter-driven reporter activity was monitored continuously over a 3- or 16-h period from 12 individual cells in six independent experiments. Note that gene expression in these cells was rarely constant but showed distinct short- and long-term changes consistent with our earlier observations (29).

Together, these results demonstrate that the destabilized protein is functional in single living cells and is produced at a rate sufficient to enable unequivocal detection of reporter activity. Although other factors such as uciferase mRNA stability and processing influence the reporter activity, the availability of this shorter-lived luciferase enzyme provides a more responsive reporter system. This reporter should be useful in understanding transient dynamic changes in gene expression that occur spontaneously under basal conditions or in response to gene activating or gene-inhibiting secretagogues. 


\section{ACKNOWLEDGMENTS}

The authors would like to thank Dr. Guy Leclerc for helpful comments and discussion, members of the Frawley laboratory for critical reading of the manuscript and David C. Leaumont for technical assistance. This work was supported by grant NIH DK38215 38215 to L.S.F.

\section{REFERENCES}

1.Castaño, J.P., W.J. Faught and L.S. Frawley. 1998. Multiple measurements of gene expression in single, living cells enable molecular analysis of endocrine cell heterogeneity. Ann. NY Acad. Sci. 839:336-340.

2.Castaño, J.P., R.D. Kineman and L.S. Fraw ley. 1996. Dynamic monitoring and quantification of gene expression in single, living cells: A molecular basis for secretory cell heterogeneity. Mol. Endocrinol. 10:500-605.

3.Devine, J.H., G.D. Kutuzova, V.A. Green, N.N. Ugarova and T.O. Baldwin. 1993. Luciferase from the East European firefly Luciola mingrelica: cloning and nucleotide sequence of the cDNA, overexpression in Escherichia coli and purification of the enzyme. Biochim. Biophys. Acta 1173:121-132.

4.De Wet, J.R., K.V. Wood, M. DeLuca, D.R. Helinski and S. Subramani. 1987. Firefly luciferase gene: structure and expression in mam malian cells. Mol. Cell Biol. 7:725-737.

5.Frawley, L.S., W.J. Faught, J. Nicholson and B. Moomaw. 1994. Real time measurement of gene expression in living endocrine cells. Endocrinol. 135:468-471.

6.Ghoda, L., M.A. Phillips, K.E. Bass, C.C. Wang and P. Coffino. 1990. Trypanosome ornithine decarboxylase is stable because it lacks sequences found in the carboxyl terminus of the mouse enzyme which target the latter for intracellular degradation. J. Biol. Chem. 265:11823-11826.

7.Ghoda, L., T. van Daalen Wetters, M. Macrae, D. Ascherman and P. Coffino. 1989. Prevention of rapid intracellular degradation of ODC by a carboxyl-terminal truncation. Science. 243:1493-1495.

8.Hayashi, S. and Y. Murakami. 1995. Rapid and regulated degradation of ornithine decarboxylase. Biochem. J. 306:1-10.

9.Heby, O. and L. Persson. 1990. Molecular genetics of polyamine synthesis in eukaryotic cells. Trends Biochem. Sci. 15:153-158.

10.Hershko, A. and A. Ciechanover. 1992. The ubiquitin system for protein degradation. Annu. Rev. Biochem. 61:761-807.

11.Kahana, C. and D. Nathans. 1985. Nucleotide sequence of murine ornithine decarboxylase mRNA. Proc. Natl. Acad. Sci. USA 82:16731677.

12.Li, X. and P. Coffino. 1993. Degradation of ornithine decarboxylase: exposure of the C-terminal target by a polyamine-inducible inhibitory protein. Mol. Cell. Biol. 13:2377-2383.

13.Li, X., X. Zhao, Y. Fang, X. Jiang, T. Duong,
C. Fan, C.C. Huang and S.R. Kain. 1998 Generation of destabilized green fluorescent protein as a transcription reporter. J. Biol. Chem. 273:34970-34975.

14.Loetscher, P., G. Pratt and M. Rechsteiner. 1991. The C terminus of mouse ornithine decarboxylase confers rapid degradation on dihydrofolate reductase. J. Biol. Chem. 266:1121311220.

15.Lorenz, W.W., M.J. Cormier, D.J. O'Kane, D. Hua, A.A. Escher and A.A. Szalay. 1996 Expression of the Renilla reniformis luciferase gene in mammalian cells. J. Biolumin. Chemilumin. 11:31-37.

16.Lorenz, W.W., R.O. McCann, M. Longiaru and M.J. Cormier. 1991. Isolation and expression of a cDNA encoding Renilla reniformis luciferase. Proc. Natl. Acad. Sci. USA 88:443844342.

17.Masuda, T., H. Tatsumi and E. Nakano. 1989. Cloning and sequence analysis of cDNA for luciferase of a Japanese firefly, Luciola cruciata. Gene 77:265-270.

18.McDonnell, D.P. and M.E. Goldman. 1994 RU486 exerts antiestrogenic activities through a novel progesterone receptor A form-mediated mechanism. J. Biol. Chem. 269:11945-11949.

19.Núñez, L., W.J. Faught and L.S. Frawley. 1998. Episodic gonadotropin-releasing hormone gene expression revealed by dynamic monitoring of luciferase reporter activity in single, living neurons. Proc. Natl. Acad. Sci. USA 95:9648-9653.

20.Obrig, T.G., W.J. Culp, W.L. McKeehan and B. Hardesty. 1971. The mechanism by which cycloheximide and related glutarimide antibiotics inhibit peptide synthesis on reticulocyte ribosomes. J. Biol. Chem. 246:174-181.

21.Rechsteiner, M. 1990. PEST sequences are signals for rapid intracellular proteolysis. Semin. Cell Biol. 1:433-440.

22.Rechsteiner, M. and S.W. Rogers. 1996. PEST sequences and regulation by proteolysis. Trends Biochem. Sci. 21:267-271.

23.Rogers, S., R. Wells and M. Rechsteiner. 1986. Amino acid sequences common to rapidly degraded proteins: the PEST hypothesis. Science 234:364-368

24.Rutter, G.A., H.J. Kennedy, C.D. Wood, M.R.H. White and J.M. Tavaré. 1998. Realtime imaging of gene expression in single living cells. Chem. Biol. 5:R285-R290.

25.Sambrook, J., E.F. Fritsch and T. Maniatis. 1989. Molecular Cloning: A Laboratory Manual, 2nd ed. CSH Laboratory Press, Cold Spring Harbor, NY

26.Stemmer, W.P.C., A. Crameri, K.D. Ha, T.M. Brennan and H.L. Heyneker. 1995. Singlestep assembly of a gene and entire plasmid from large numbers of oligodeoxyribonucleotides. Gene 164:49-53.

27.Thompson, J.F., L.S. Hayes and D.B. Lloyd. 1991. Modulation of firefly luciferase stability and impact on studies of gene regulation. Gene 103:171-177.

28. Villalobos, C., W.J. Faught and L.S. Frawley. 1999. Dynamics of stimulus-expression coupling as revealed by monitoring of prolactin promoter-driven reporter activity in individual, living mammotropes. Mol. Endocrinol. 13:1718-1727.

29.Willard, S.T., W.J. Faught and L.S. Frawley.
1997. Real-time monitoring of estrogen-regulated gene expression in single, living breast cancer cells: a new paradigm for the study of molecular dynamics. Cancer Res. 57:44474450.

30.Willard, S.T. and L.S. Frawley. 1998. Phytoestrogens have agonistic and combinatorial effects on estrogen-responsive gene expression in MCF-7 human breast cancer cells. Endocrine 8:117-121.

31.Wilson, T. and J.W. Hastings. 1998. Bioluminescence. Annu. Rev. Cell Dev. Biol. 14:197230.

32.Wood, K.V., Y.A. Lam, H.H. Seliger and W.D. McElroy. 1989. Complementary DNA coding click beetle luciferases can elicit bioluminescence of different colors. Science 244:700-702.

Received 24 February 2000; accepted 3 May 2000.

\section{Address correspondence to:}

Dr. L. Stephen Frawley

Laboratory of Molecular Dynamics

Department of Cell Biology and Anatomy

Medical University of South Carolina,

171 Ashley Avenue

Charleston, SC 29425, USA

e-mail: frawleys@musc.edu 